\title{
Reflexión
}

\section{Irrupción del professorado como intelectuales críticos em el contexto de pandemia, ien buena}

hora!

\author{
FREDDY SÁNCHEZ IBARRA
}

MANUEl PÉREZ-TRONCOSO iD

\footnotetext{
a Licenciado en Historia, Diplomado en Estudios Políticos y Postitulado en Filosofía y Educación de la Universidad de Chile y Magíster en educación de la Universidad Mayor. Tiene publicaciones en el ámbito de la historia, literatura y educación. Además es coautor de un libro de historia oral de la comuna de Ercilla financiado a través de un proyecto FONDART.

b Profesor de Historia y Geografia, Universidad del Biobio Magister en Políticas Sociales y Gestión Local, Universidad Arcis Ph.D. Student in Educational Policies, Organization, and Leadership, concentration in Student in Global Studies in Education. University of Illinois at Urbana-Champaign
}

Rev. Caminhos da Educação: diálogos, culturas e diversidades, Teresina, v. 2, n. 2, p.103-,108, mai./ago. 2020 
Si tuviéramos que imaginar una característica de la educación chilena neoliberal, más allá de su histórica y criticada dinámica de mercado, obligatoriamente deberíamos hablar de la ausencia de voces docentes en el diseño de políticas educativas. Ser docente en Chile ha implicado prescindir de cualquier ejercicio teórico que otorgue significado a su experiencia educativa. De hecho, las políticas educativas han atomizado el rol de profesores, acotándolo solo a un rol ejecutor y por ende mermando el carácter crítico, propio de su cualidad de intelectuales transformativos (Giroux 1997; Apple, 1997)

Los problemas asociados a la ausencia de participación docente son propios del énfasis que se ha puesto en los factores instrumentales de la vida escolar, que buscan una concepción pedagógica polarizada. Se fundan en engrosar la frontera entre política educacional, diseño curricular, gestión y la solitaria (y desapegada también) implementación en el aula, práctica supervigilada por evaluaciones de desempeño institucional y nacional como el SIMCE, vigilancia mediática, y políticas de tercer orden que intentan mejorar la educación basadas en estímulo económicos a cambio del aumento en resultados de pruebas estandarizadas, como es el caso de la ley de Subvención Escolar Preferencial (SEP) y el Sistema Nacional de Evaluación de Desempeño (SNED). Estos factores, han puesto en entredicho ese carácter contextualizado y transformador que la quintaesencia de la función del profesor-a.

Además, la escasa participación del profesorado tiene raíces en su formación docente, que aún arrastra un daño académico considerable en sus escuelas de pedagogía durante y posterior a la dictadura. La escisión del Pedagógico de la Universidad de Chile, por ejemplo, y la pérdida de un proyecto nacional de formación docente liderado por la Escuela Normal, conllevó a que la reflexión sobre la naturaleza de los principios teóricos de la política o práctica educativa fuera jibarizada en favor de la masificación (y cristalización) de la idea de aprender "cómo enseñar", "con qué instrumentos hacerlo", "como evaluar" y "con qué mecanismos hacerlo".

Rev. Caminhos da Educação: diálogos, culturas e diversidades, Teresina, v. 2, n. 2, p.103-, 108, mai./ago. 2020 


\section{Imupción del professorado como intelectuales aríticos em el contexto de pandemia, ien buena hora!}

El lenguaje constructivista de las eternas reformas educacionales iniciadas en 1994, relegaron a las y los profesores de una participación sustantiva y crítica tanto en su formación como en el ejercicio docente haciendo común el "cómo" enseñar sin su paso por el cedazo crítico, filosófico, político y menos su aproximación al debate del canon de "qué" o "para qué" enseñar, o sea, sin correspondencia en el plano de la cultura escolar, propio del triunfo de fuerzas modernizadoras que mantiene conductas inconsistentes incluso a la misma Modernidad (Habermas, 1989). A pesar de lo anterior, a partir de la segunda mitad de la década pasada, hemos sido testigos de nuevas voces en la formación docente proveniente de un fructífero intercambio entre el profesorado organizado y académicos jóvenes, que situados desde la justicia social han extendido el análisis crítico de las políticas de formación docente (Fernández, 2018) y el rol de una pedagogía culturalmente relevante (Ladson-Billings, 2014; PeñaSandoval \& Montecinos, 2016).

Otra dimensión de la irrupción docente ha sido su participación en el movimiento estudiantil. Pues, al mirar la trayectoria del movimiento, se puede observar una participación escalada de actores educativos, iniciado por estudiantes secundarios en 2006, seguido por universitarios en 2011 y finalmente profesores-as en 2014. Ese año, docentes manifestaron organizadamente su disidencia al diseño de las políticas educativas — agobio laboral y precarización laboral — con un alcance nacional no visto en los últimos treinta años. Desde esa fecha que la asociación gremial presenta una directiva y organización nacional participativa, que incluye organizaciones docentes de base y una agenda de trabajo sindical y de reflexión curricular. En este sentido, anterior a la situación de pandemia que estamos viviendo, el Colegio de Profesores y otras organizaciones de profesores/as ya estaban explorando una reflexión curricular en red con académicos y organizaciones educativas extendidas, cómo la campaña Alto al Simce.

Es así, que los principales cambios generados por el COVID-19: producción de material educativo a distancia, reorganización curricular, desigualdad de acceso a internet en el alumnado y la amenaza permanente de retorno a clases sin las condiciones sanitarias; han generado un espacio de intervención crítica de docentes. En gran manera, la poca claridad en las propuestas desde la política pública facilitó que profesores-as de todo el país estén resignificando el currículo escrito

Rev. Caminhos da Educação: diálogos, culturas e diversidades, Teresina, v. 2, n. 2, p.103-,108, mai./ago. 2020 
(oficial) para dar una respuesta profesional, critica, creativa que estructura una institucionalidad educativa para enfrentar el confinamiento social. No es difícil identificar ciertos ajustes, por ejemplo, la articulación de Objetivos de Aprendizaje (OA) y aspectos formativos proyectado hacia comunidad remota $^{1}$ o física, cuando los y las estudiantes tiene problemas de acceso a internet.

Además, los y las docentes se están capacitando de manera autodidacta ${ }^{2}$ en el uso de tecnologías (RRSS, SRI, grabando clases, disponiéndolas en canes de YouTube, utilizando diversos softwares) dotando a las mismas de sentido (contexto teórico) y contextualizándolas a las múltiples realidades particulares que se aprecian en el largo Chile (contexto concreto). Entonces, en cierto sentido podemos afirmar que la pandemia está siendo una oportunidad para desplegar una pedagogía más humana y empática hacia los y las estudiantes, que supera significativamente la capacidad de respuesta y prioridades de la institucionalidad educativa. Hoy, profesores y profesoras están resignificando su labor y la misión de la docencia develando y afrontando la brutal desigualdad social que la pandemia nos muestra en espacios domésticos. En cierta forma, la octava y novena cartas [de que ]Paulo Freire (1994) se materializan en el actual desafío de educar, ya que profesores-as están integrando el contexto concreto de la pandemia a través de la creación de nuevos y variados formatos virtuales de enseñanzaaprendizaje.

No obstante, el carácter crítico y transformador que resaltamos se materializa en escenarios laborales llenos de tensiones y precariedades. Por una parte, existe abundancia de ejemplos para determinar que la respuesta docente a la situación de pandemia está sucediendo a escala individual y sin resonancia en los equipos directivos y/o colegas de establecimiento. Además, el COVID-19 demanda horas extras de trabajo no remuneradas, turnos éticos docentes en los establecimientos sin función pedagógica clara, y aunque no sea algo nuevo para los y las profesores, el uso de recursos individuales - internet, computador propio y capacitación - para garantizar el desarrollo de las clases y guías. Todos estos elementos de contexto no hacen más

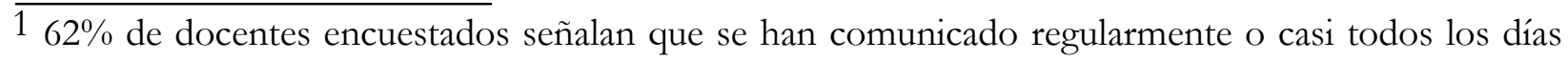
con sus estudiantes. $65 \%$ de profesores consultados utiliza chat (un 53\% mail) para entregar y dar apoyo u orientaciones a sus estudiantes. Fuente: www.miradadocentes.cl

2 Sin embargo, reconocen que necesitan apoyo. Un 80\% de docentes consultados indica que la necesidad de recibir información para afrontar la crisis. Fuente: www.miradadocentes.cl

Rev. Caminhos da Educação: diálogos, culturas e diversidades, Teresina, v. 2, n. 2, p.103-,108, mai./ago. 2020 


\section{Imupción del professorado como intelectuales aríticos em el contexto de pandemia, ien buena hora!}

que resaltar la respuesta docente y nos invita a estudiar con mayor detención las redes de contención

y creación ${ }^{3}$ surgidas durante el tiempo de pandemia. Ejemplo de aquello es la apuesta por la nuclearización del currículo (Caro, 2020), que apela a retornar a los objetivos fundamentales de cada asignatura en reemplazo de OA y su implementación considerando las características particulares de cada contexto.

En este sentido, la nuclearización facilita mayor diversidad y traducción curricular según el contexto concreto de cada estudiante, distinto de la priorización curricular sugerida por el Ministerio de Educación (2020) autolimitada a orientar desde el contexto teórico (currículo oficial) para alcanzar un mínimo "imprescindible de objetivos" que evidencien dominio en cada asignatura no obstante que el confinamiento social es una situación extraordinaria e histórica. Adicionalmente, el Centro de Investigación Avanzada en Educación (CIAE), docentes y miembros de la sociedad civil hablan de una priorización emocional (CIAE, 20 de abril, 2020) que se haga cargo de las incertidumbres propias de educar en un contexto de confinamiento social.

En definitiva, hay un horizonte que se abre para los docentes como intelectuales transformativos, para que sean partícipes y críticos del momento histórico post pandemia. Así, se debe hacer un trabajo de rastreo, de investigación de prácticas, experiencias, decisiones docentes en cuanto a la implementación curricular, generar hallazgos, elaborar hipótesis. Con ello, los-as profesores- as deben ser protagonistas tanto para hacer frente a lo que se ha perdido en este período, como de la misión educadora para la formación misma de una teoría, su teoría. Deben abrirse espacio para formar parte nodal en la discusión de las grandes decisiones curriculares, económicas, laborales, de gestión, de política educativa y otras con un discurso articulado y sólido. Sólo con dichas condiciones podrán ser parte integrante y vital (papel que les corresponde) como renovado pilar del sistema educativo chileno.

Rev. Caminhos da Educação: diálogos, culturas e diversidades, Teresina, v. 2, n. 2, p.103-,108, mai./ago. 2020 
3 Observatorio Chileno de Políticas Educativas (OPECH), Núcleo de Estudio Curriculum, Conocimiento y Experiencia Escolar (NECCEE) y Movimiento de Unidad Docente (MUD), entre otras.

Rev. Caminhos da Educação: diálogos, culturas e diversidades, Teresina, v. 2, n. 2, p.103-,108, mai./ago. 2020 


\section{Referencias}

Apple, M. W. (1997). Educación y poder (segunda reimpresión). Paidos. Barcelona.

Caro, M. (1 de junio de 2020) Nuclearización: la propuesta del magisterio para abordar el curriculum ante la pandemia. Recuperado en https://www.colegiodeprofesores.cl/2020/06/01/nuclearizacion-lapropuesta-del- magisterio-para-abordar-el-curriculum-durante-lapandemia.

CIAE (20 de abril de 2020) Docentes y expertos coincidieron en necesidad de priorizar la educación emocional en tiempos de coronavirus. Recuperado en http:/ / ciae.uchile.cl/index.php?page $=$ view noticias\&langSite $=$ es\&id $=187$ $\underline{8}$

Fernández, M. B. (2018). Framing teacher education: Conceptions of teaching, teacher education, and justice in Chilean national policies. Education Policy Analysis Archives, 26(34).

Freire, P. (1994): Cartas a quien pretende enseñar. Siglo XXI editores. México.

Giroux, H. (1997). Los Profesores como Intelectuales: Hacia una pedagogía crítica del aprendiraje. Paidós. España

Habermas, J. (1989) "La modernidad: Un proyecto incompleto". En Nicolás Casullo: El debate modernidad post-modernidad. Ediciones Punto Sur. Buenos Aires

Ladson-Billings, G. (2014). Culturally relevant pedagogy 2.0: aka the remix. Harvard Educational Review, 84(1), 74-84.

MINEDUC (2020) Fundamentos de la Priorización Curricular Covid-19.

Recuperado en https://curriculumnacional.mineduc.cl/614/articles179650 archivo 01.pdf

Peña-Sandoval, C., \& Montecinos, C. (2016). Formación inicial de docentes desde una perspectiva de justicia social: Una aproximación teórica. Revista Internacional de Educación Para La Justicia Social (RIEJS).

houver). Título e número da legislação. Dados da fonte na qual foi publicado o documento.

RECEBIDO: 01/06/2020

APROVADO:03/08/ 2020
RECEIVED: 01/06/2020

APPROVED: 03/08/ 2020
RECIBIDO: 03/08/ 2020

APROBADO: 03/08/ 2020

Rev. Caminhos da Educação: diálogos, culturas e diversidades, Teresina, v. 2, n. 2, p.103-,108, mai./ago. 2020 